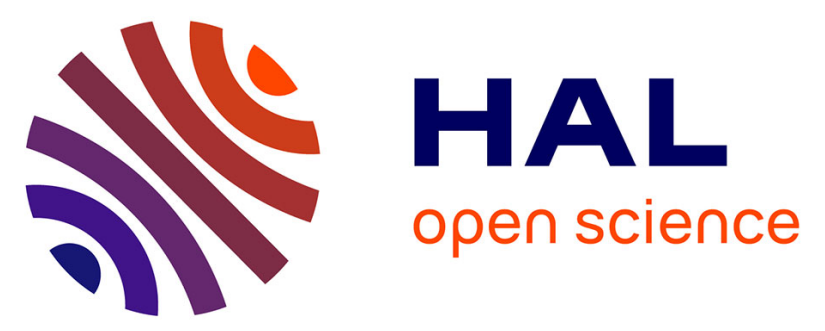

\title{
Molecular mobility interpretation of the dielectric relaxor behavior in fluorinated copolymers and terpolymers
}

\author{
Jean-Fabien Capsal, Eric Dantras, Colette Lacabanne
}

\section{To cite this version:}

Jean-Fabien Capsal, Eric Dantras, Colette Lacabanne. Molecular mobility interpretation of the dielectric relaxor behavior in fluorinated copolymers and terpolymers. Journal of Non-Crystalline Solids, 2013, vol. 363, pp. 20-25. 10.1016/j.jnoncrysol.2012.12.008 . hal-00818214

\section{HAL Id: hal-00818214 https://hal.science/hal-00818214}

Submitted on 26 Apr 2013

HAL is a multi-disciplinary open access archive for the deposit and dissemination of scientific research documents, whether they are published or not. The documents may come from teaching and research institutions in France or abroad, or from public or private research centers.
L'archive ouverte pluridisciplinaire HAL, est destinée au dépôt et à la diffusion de documents scientifiques de niveau recherche, publiés ou non, émanant des établissements d'enseignement et de recherche français ou étrangers, des laboratoires publics ou privés. 


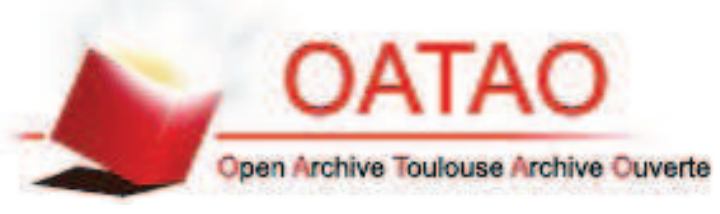

\section{Open Archive Toulouse Archive Ouverte (OATAO)}

OATAO is an open access repository that collects the work of Toulouse researchers and makes it freely available over the web where possible.

This is an author-deposited version published in: http://oatao.univ-toulouse.fr/ Eprints ID: 8789

To link to this article: DOI: $10.1016 /$ j.jnoncrysol.2012.12.008

URL : $\underline{\text { http://dx.doi.org/10.1016/j.jnoncrysol.2012.12.008 }}$

\section{To cite this version:}

Capsal, Jean-Fabien and Dantras, Eric and Lacabanne, Colette Molecular mobility interpretation of the dielectric relaxor behavior in fluorinated copolymers and terpolymers. (2013) Journal of Non-Crystalline Solids, vol. 363 pp. 20-25. ISSN 0022-3093

Any correspondence concerning this service should be sent to the repository administrator: staff-oatao@ listes.diff.inp-toulouse.fr 


\title{
Molecular mobility interpretation of the dielectric relaxor behavior in fluorinated copolymers and terpolymers
}

\author{
Jean-Fabien Capsal ${ }^{\mathrm{b}}$, Eric Dantras ${ }^{\mathrm{a}, *}$, Colette Lacabanne ${ }^{\mathrm{a}}$ \\ a Physique des Polymères, Institut CARNOT-CIRIMAT, Université Paul Sabatier, 31062 Toulouse, France \\ b LGEF, INSA Lyon, 69621 Villeurbanne, France
}

Keywords:

Dielectric relaxations;

Thermostimulated currents;

Relaxor;

Terpolymers:

Electroactive polymers

\begin{abstract}
A B S T R A C T
Thermo Stimulated Current and Dynamic Dielectric Spectroscopy have been applied to investigate dielectric relaxation modes of poly(vinylidene-fluoride-trifluoroethylene) copolymer and poly(vinylidene-fluoridetrifluoroethylene-chlorofluoroethylene) terpolymer. The aim of this work is to check the molecular origin of the ferroelectric relaxor behavior of the terpolymer. The combination of data obtained by both dielectric methods allows us to describe the molecular mobility of the amorphous phase and the cooperativity of the order/disorder dipolar transition in the crystalline phase. The introduction of 1,1-chlorofluoroethylene units in the main chain induces an increase of the Cooperative Rearranging Region size associated with less ordered and smaller crystallites. This morphological evolution is responsible of a lack of cooperativity and it explains the dielectric relaxor behavior of the poly(vinylidene-fluoride-trifluoroethylene-chloroethylene) terpolymer.
\end{abstract}

\section{Introduction}

Since the discovery of the piezoelectric behavior of poly(vinylidenefluoride) - PVDF by Kawai [1] and the understanding of the molecular origin of this electroactivity [2-5], organic ferroelectric materials have attracted the interest of researchers for their potential use in specific applications such as low weight and flexible sensors [6,7], electromechanical devices $[8,9]$ and high-K capacitors $[10,11]$. Many classes of polymers such as odd-polyamides [12], even odd polyamide copolymers [13], have shown piezoelectric and pyroelectric activities. Nevertheless, the poly(vinylidene-fluoride-trifluoroethylene) $-\mathrm{P}(\mathrm{VDF}-\mathrm{TrFE})$ copolymer $[14,15]$ and the poly(vinylidene-fluoride-trifluoroethylenechlorofluoroethylene) - $\mathrm{P}$ (VDF-TrFE-CFE) terpolymer [16,17]. For electroactive applications, $\mathrm{P}(\mathrm{VDF}-\mathrm{TrFE})$ copolymer is the most useful polymer because of the low poling field required to give ferroelectric behavior and high dielectric permittivity, compared with other ferroelectric polymers. Another important point is that this copolymer does not require any mechanical stretching before the poling process. Recently, it has been demonstrated that an electron irradiation of the P(VDF-TrFE) and the random incorporation of the CFE unit in P(VDF-TrFE-CFE) can achieve an electrostrictive strain greater than 5\% [18-20] (higher than the $\mathrm{P}(\mathrm{VDF}-\mathrm{TrFE})$ copolymer). This large electrostrictive behavior has been attributed to the relaxor behavior induced by defects in the crystalline phase caused by the irradiation or introduction of CFE units which is responsible of a high dielectric permittivity at room temperature $[21,22]$. The introduction of random defects broadens the ferroelectric transition and reduces the ferroelectric-paraelectric transition

\footnotetext{
* Corresponding author. Tel.: + 33561556456.

E-mail address: eric.dantras@univ-tlse3.fr (E. Dantras).
}

temperature. However, the molecular origin of the dielectric relaxor behavior of fluorinated terpolymer or electron irradiated copolymer remains obscure.

The main objective of this paper is to investigate the molecular mobility over a wide frequency range by means of thermal and dielectric analysis. Thermostimulated current analysis of the terpolymer and the copolymer was used for the first time and allows us to give a molecular interpretation of the cooperativity and of the ferroelectric/paraelectric transition, called Curie transition, in fluorinated polymers.

\section{Experimental section}

\subsection{Samples elaboration}

Two kinds of fluorinated polymers were used in this study: the poly(vinylidene-fluoride-trifluoroethylene) (P(VDF-TrFE) 70-30 mol.\%) copolymer and the poly(vinylidene-fluoride-trifluoroethylenechlorofluoroethylene) (P(VDF-TrFE-CFE) 55.8-35-9.2 mol.\%) terpolymer. Both of them have been purchased from Piezotech (France). $\mathrm{P}$ (VDF-TrFE-CFE) was synthesized by a suspension method with an oxygen-activated initiator [23].

For dielectric experiments, both as-received polymer powders were hot pressed $20{ }^{\circ} \mathrm{C}$ above their melting temperature. Films of $100 \mu \mathrm{m}$ in thickness and $20 \mathrm{~mm}$ in diameter were obtained.

\subsection{Standard differential scanning calorimetry}

Standard differential scanning calorimetry (DSC) measurements were performed using a DSC/TMDSC 2920 setup. The sample temperature was calibrated using the onset of melting of tin $\left(\mathrm{T}_{\mathrm{m}}=231.88^{\circ} \mathrm{C}\right)$, 
indium $\left(\mathrm{T}_{\mathrm{m}}=156.6^{\circ} \mathrm{C}\right)$ and cyclohexane $\left(\mathrm{T}_{\mathrm{m}}=6{ }^{\circ} \mathrm{C}\right)$ with a heating rate of $\mathrm{q}_{\mathrm{h}}=+5{ }^{\circ} \mathrm{C} \mathrm{min}^{-1}$. The heat-flow was calibrated with the heat of fusion of indium $\left(\Delta \mathrm{H}=28.45 \mathrm{~J} \mathrm{~g}^{-1}\right)$ and the baseline was corrected using sapphire. DSC experiments were systematically carried out over a temperature range from the equilibrium state (in order to remove the effect of previous thermal history) $\mathrm{T}_{\mathrm{eq}}=\mathrm{T}_{\mathrm{m}}+20^{\circ} \mathrm{C}$ down to the glassy state $\mathrm{T}_{0}=\mathrm{T}_{\mathrm{g}}-70{ }^{\circ} \mathrm{C}$ with a constant cooling rate $\mathrm{q}_{\mathrm{c}}=+10{ }^{\circ} \mathrm{C} \mathrm{min}{ }^{-1}$, and followed by a linear heating rate $\mathrm{q}_{\mathrm{h}}=10^{\circ} \mathrm{C} \mathrm{min}^{-1}$. The crystallinity ratios of the copolymer and the terpolymer have been determined. Thanks to the heat of fusion value of the $100 \%$ crystalline homopolymer.

\subsection{Thermostimulated currents}

Complex Thermo Stimulated Currents [24] (TSC) thermograms were carried out using a TSC/RMA Analyser. For complex experiments, the sample was polarized by an electrostatic field $\mathrm{E}=3 \mathrm{kV} \mathrm{mm}^{-1}$ over a temperature range from the polarization temperature $\left(T_{p}=\right.$ $40{ }^{\circ} \mathrm{C}$ for the terpolymer and $\mathrm{T}_{\mathrm{p}}=110^{\circ} \mathrm{C}$ for the copolymer) down to the freezing temperature $\mathrm{T}_{0}$ (LNT temperature) with a constant cooling rate. Then, the field was turned off and the depolarization current was recorded with a controlled heating rate $\left(\mathrm{q}_{\mathrm{h}}=+7{ }^{\circ} \mathrm{C} \mathrm{min}^{-1}\right)$; the equivalent frequency of the TSC thermogram was $\mathrm{f}_{\mathrm{eq}} \sim 10^{-2}-10^{-3} \mathrm{~Hz}$. Elementary TSC thermograms were obtained with a polarization window of $5{ }^{\circ} \mathrm{C}$. The field was removed and the sample cooled to a temperature $\mathrm{T}_{\mathrm{cc}}=\mathrm{T}_{\mathrm{p}}-30^{\circ} \mathrm{C}$. The depolarization current was recorded with a constant heating rate $\mathrm{q}_{\mathrm{h}}$. The series of elementary thermograms was generated by shifting the polarization window by $5{ }^{\circ} \mathrm{C}$ toward higher temperature. $\Delta \mathrm{H}$ and $\Delta \mathrm{S}$ uncertainties, extracted by this method, have been estimated near 10 and $20 \%$ respectively.

\subsection{Dynamic dielectric spectroscopy}

Dynamic Dielectric Spectroscopy (DDS) experiments were performed using a BDS400 set up covering a frequency range of $10^{-2} \mathrm{~Hz}-3.10^{6} \mathrm{~Hz}$, with 10 points per decade. Experiments were carried out in a temperature range from $-100{ }^{\circ} \mathrm{C}$ to $130{ }^{\circ} \mathrm{C}$. Dielectric isothermal spectra were measured every $2{ }^{\circ} \mathrm{C}$. During each frequency scan, the temperature was kept constant to $\pm 0.2{ }^{\circ} \mathrm{C}$. The real $\varepsilon_{\mathrm{T}}^{\prime}$ and imaginary $\varepsilon_{\mathrm{T}}^{\prime \prime}$ parts of the relative complex permittivity $\varepsilon_{\mathrm{T}}^{*}$ were measured as a function of frequency $\mathrm{F}$ at a given temperature $T$.

\section{Results and discussion}

\subsection{Physical structure}

Differential scanning calorimetry thermograms of the terpolymer and the copolymer are shown in Fig. 1. This experimental technique allows us to perform a quantitative and comparative study of the thermal transitions in semi-crystalline polymers. The heat capacity steps associated with the glass transition are weak. The glass transition temperatures have been approximately determined near $-29{ }^{\circ} \mathrm{C}$ and $-23{ }^{\circ} \mathrm{C}$ for the copolymer and the terpolymer respectively. For both polymers, two endothermic peaks are pointed out; according to the literature [25-27], they have been attributed respectively to the Curie transition $\left(T_{c}\right)$ and to the melting $\left(T_{m}\right)$, in the order of increasing temperature. Both are dealing with the crystalline regions of polymers.

The melting temperature of the $\mathrm{P}(\mathrm{VDF}-\mathrm{TrFE})$ copolymer is located at $\mathrm{T}_{\mathrm{m}}=152{ }^{\circ} \mathrm{C}\left(\Delta \mathrm{H}_{\mathrm{m}}=26.3 \mathrm{~J} \mathrm{~g}^{-1}\right)$; it decreases to $\mathrm{T}_{\mathrm{m}}=122{ }^{\circ} \mathrm{C}$ $\left(\Delta \mathrm{H}_{\mathrm{m}}=23 \mathrm{~J} \mathrm{~g}^{-1}\right)$ for the P(VDF-TrFE-CFE) terpolymer. The evolution of $T_{m}$ is accompanied by a weak decrease of the melting enthalpies upon introduction of CFE units in the main chain. The width at half height of the terpolymer melting peak is twice the one of the copolymer. In the same way, the peak temperature and the enthalpies of the Curie transition decrease from $\mathrm{T}_{\mathrm{C}}=102{ }^{\circ} \mathrm{C}$ (higher temperature of the bimodal [28] Curie transition) and $\Delta \mathrm{H}_{\text {Curie }}=20.8 \mathrm{~J} \mathrm{~g}^{-1}$ for $\mathrm{P}(\mathrm{VDF}-\mathrm{TrFE})$, to $\mathrm{T}_{\mathrm{c}}=19^{\circ} \mathrm{C}$ and $\Delta \mathrm{H}_{\text {Curie }}=3.3 \mathrm{~J} \mathrm{~g}^{-1}$ in the case of P(VDF-TrFE-CFE).

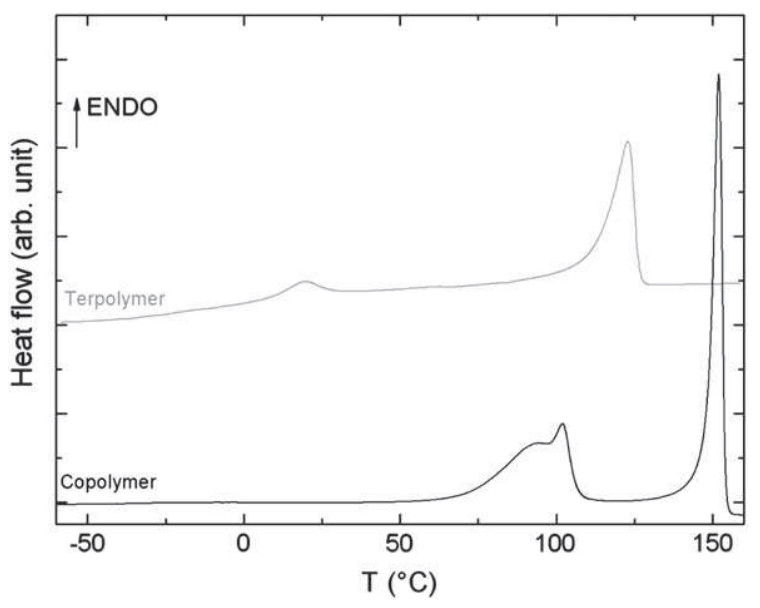

Fig. 1. DSC thermograms of the P(VDF-TrFE-CFE) terpolymer (gray line) and the $\mathrm{P}(\mathrm{VDF}-\mathrm{TrFE})$ copolymer (black line) during the heating scan.

The degree of crystallinity has been estimated near $44 \%$ for $\mathrm{P}(\mathrm{VDF}-\mathrm{TrFE})$ and $25 \%$ for P(VDF-TrFE-CFE). DSC experiments show that the introduction of CFE units highly influences the crystalline structure by creating less ordered crystallites. CFE units tend to reduce the crystallite sizes ( $\mathrm{T}_{\mathrm{m}}$ and $\mathrm{T}_{\mathrm{c}}$ decrease) and increase the morphological heterogeneity of crystallites (full-width at half-maximum of the melting peaks increase). These results are consistent with the decrease of crystallinity ratio with CFE content previously reported by Klein et al. [19] and they confirm conclusions of Bao et al. [25] study about size and quality of the crystallites.

\subsection{Dynamic dielectric relaxations}

In order to understand the dielectric relaxor behavior of P(VDFTrFE-CFE), dynamic dielectric spectroscopy and thermally stimulated currents have been used to characterize the molecular mobility over a wide frequency range. In Fig. $2-\mathrm{a} / \mathrm{b}$ the evolution of the imaginary $\left(\varepsilon^{\prime \prime}\right)$ and real $\left(\varepsilon^{\prime}\right)$ parts of the dielectric permittivity of P(VDF-TrFE-CFE) are reported as function of temperature for various frequencies ranging from $10 \mathrm{~Hz}$ to $1 \mathrm{MHz}$. Two relaxations are pointed out. The low temperature relaxation called $\alpha$ is localized near $\mathrm{T}_{\alpha}=-15{ }^{\circ} \mathrm{C}$ at $10 \mathrm{~Hz}$. This relaxation has a Vogel-Tammann-Fulcher (VTF) behavior which has been associated with the dielectric manifestation of the glass transition. It is in agreement with previously published results [25]. The high temperature relaxation located near $\mathrm{T}_{\mathrm{\alpha c}}=15{ }^{\circ} \mathrm{C}$ at $10 \mathrm{~Hz}$ has been attributed to the dielectric manifestation of the Curie transition according to DSC results. The thermal evolution of the dielectric manifestation of the Curie process is more complex than the one of the $\alpha$ relaxation. For frequencies ranging from $10 \mathrm{~Hz}$ to $15 \mathrm{kHz}$, this relaxation is a quasi-isothermal process; it is consistent with a first order Curie transition. At $\mathrm{f}_{\mathrm{m}}=15 \mathrm{kHz}$, a merging between the $\alpha$ and Curie relaxations takes place. Above $f_{m}$, this merging gives rise to a unique relaxation mode with a thermal evolution similar to the $\alpha$ mode. The relaxor behavior of the terpolymer seems to be governed by the $\alpha$ process.

The real and imaginary parts of $\mathrm{P}(\mathrm{VDF}-\mathrm{TrFE})$ are shown on Fig. 3-a/b. In both cases, two relaxations are found similar to the terpolymer. The VTF $\alpha$ process is located near $\mathrm{T}_{\alpha}=-25^{\circ} \mathrm{C}$ at $\mathrm{f}=10 \mathrm{~Hz}$ and the Curie peak is located at $110{ }^{\circ} \mathrm{C}$ according to DSC measurements: $\mathrm{P}(\mathrm{VDF}-\mathrm{TrFE})$ is a ferroelectric polymer with an isothermal first order Curie transition. The dielectric strength $\Delta \varepsilon$ and the dielectric energy losses of the $\alpha$ relaxation in the terpolymer are higher than those of the copolymer. The high values of $\varepsilon^{\prime}$ and $\varepsilon^{\prime \prime}$ of the terpolymer above $\mathrm{f}_{\mathrm{m}}$ are attributed to the superposition of the $\alpha$ and Curie processes. 

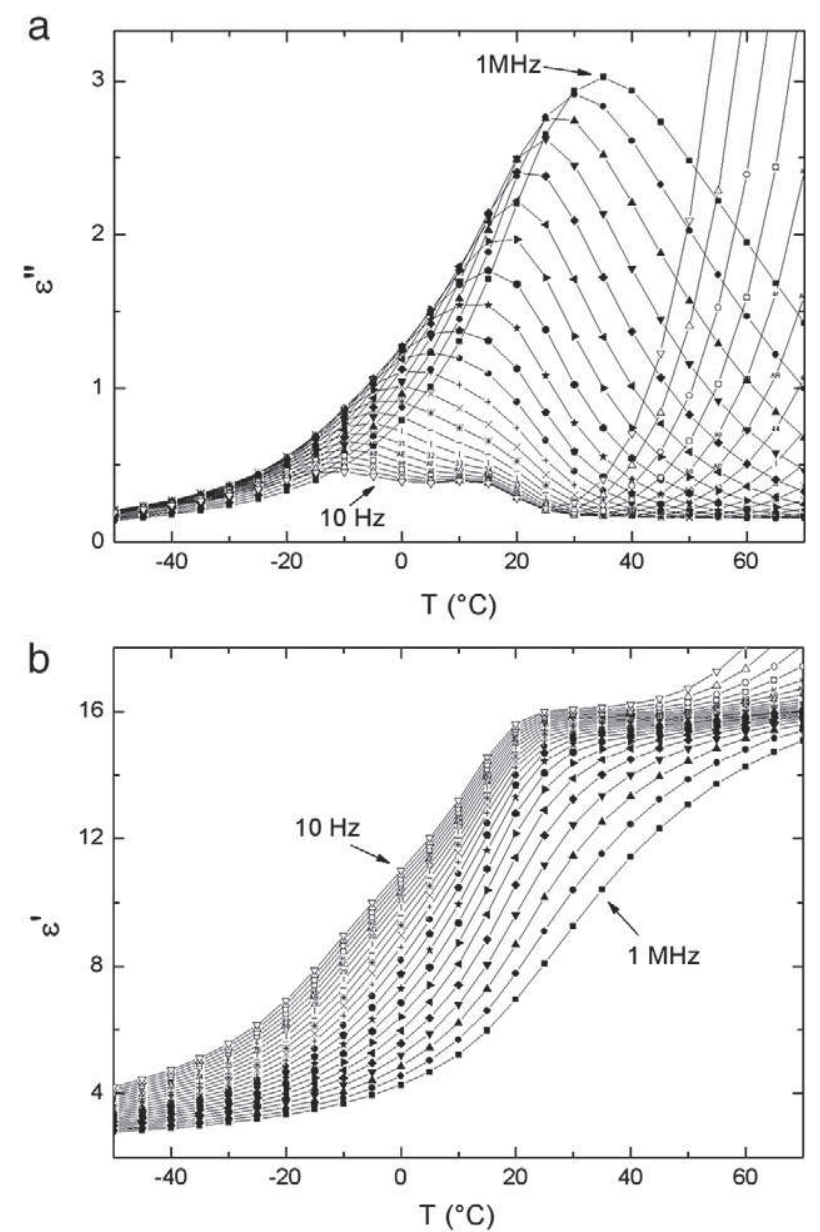

Fig. 2. Imaginary $\varepsilon^{\prime \prime}$ (a) and real $\varepsilon^{\prime}$ (b) parts of the dielectric permittivity of the $\mathrm{P}(\mathrm{VDF}-\mathrm{TrFE}-\mathrm{CFE})$ terpolymer versus temperature for frequencies ranging from $10 \mathrm{~Hz}$ to $1 \mathrm{MHz}$. Lines are given as guides to the eye.

\subsection{Fine structure of dielectric relaxations}

The complex thermostimulated current (TSC) and the elementary TSC thermograms of $\mathrm{P}(\mathrm{VDF}-\mathrm{TrFE}-\mathrm{CFE})$ and $\mathrm{P}$ (VDF-TrFE) are reported in Fig. 4-a and b/c respectively. For the terpolymer, two relaxation modes are shown. The $\alpha$ and Curie modes are located at $\mathrm{T}_{\alpha}=-15^{\circ} \mathrm{C}$ and $\mathrm{T}_{\alpha c}=25{ }^{\circ} \mathrm{C}$ respectively; these values are consistent with low frequencies data from DSC and DDS. The $\alpha$ mode is attributed to the dielectric manifestation of the glass transition. For the P(VDF-TrFE), $\alpha$ and Curie relaxations are centered around $\mathrm{T}_{\alpha}=-24{ }^{\circ} \mathrm{C}$ and $\mathrm{T}_{\alpha \mathrm{c}}=103{ }^{\circ} \mathrm{C}$ respectively. The $T_{\alpha}$ value is slightly different from a previous work [29] determined near $-20^{\circ} \mathrm{C}$. This difference has been associated with the influence of the Curie mode at higher temperature. We note that the Curie mode of the terpolymer is broader than the one of the copolymer. We assume that each process can be analyzed as a distribution of relaxation times; we extract from the elementary processes the activation enthalpies and the whole polarization of the dipolar relaxation [30-33]. Fig. 5 reports the activation enthalpies $\Delta H$ versus temperature.

The evolution of the $\alpha$ process of the copolymer and the terpolymer is very similar. In both cases, the activation enthalpy values depart from the null activation entropy line [34]. The delocalized mobility behavior of the dipolar entities involved in this process is characteristic of the relaxation associated with the glass transition. The maximal activation enthalpy of the terpolymer $\alpha$ mode is higher than for the copolymer. As previously shown by DSC, the CFE units strongly affect the crystalline regions. As a consequence, the Curie transition activation enthalpies of the terpolymer and copolymer are very different. For the terpolymer, the activation enthalpies are

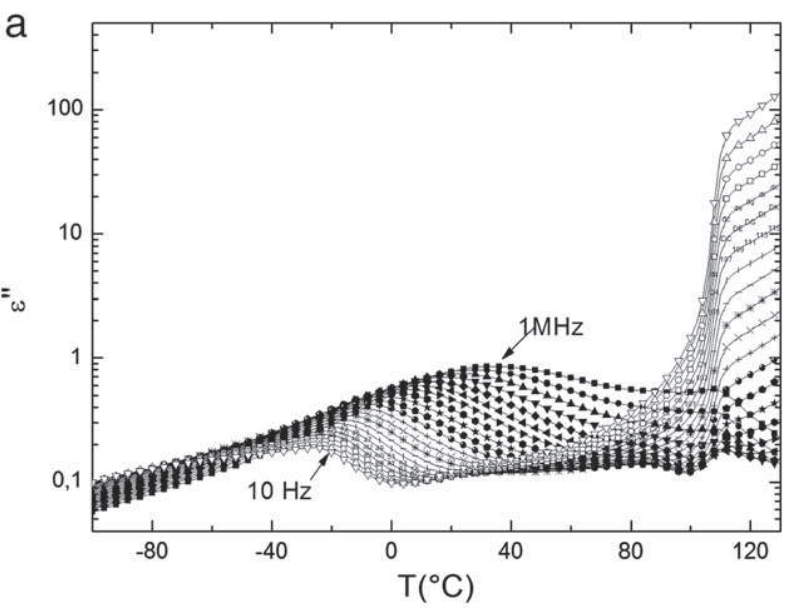

b

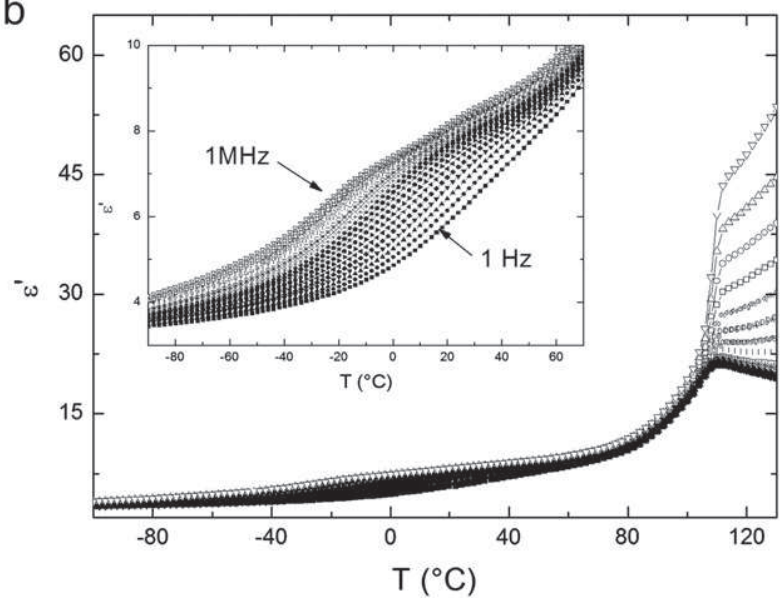

Fig. 3. Imaginary $\varepsilon^{\prime \prime}$ (a) and real $\varepsilon^{\prime}$ (b) parts of the dielectric permittivity of the $\mathrm{P}(\mathrm{VDF}-\mathrm{TrFE})$ copolymer versus temperature for frequencies ranging from $10 \mathrm{~Hz}$ to $1 \mathrm{MHz}$. Lines are given as guides to the eye.

close to those of the $\alpha$ relaxation and are not influenced by the peak temperature. The delocalization of the Curie process is of the same order than for the $\alpha$ process. In other words, CFE units give rise to less ordered crystalline regions. For the copolymer, the evolution of the activation enthalpies associated with the Curie transition clearly indicates a more delocalized mobility due to long range cooperativity.

The polarization $P_{0}$ of each elementary processes, proportional to the number of dipoles, is shown in Fig. 6 -a and b for the terpolymer and the copolymer respectively. For both polymers, two peaks are distinguishable. They are associated with the maximum of $\alpha$ and Curie relaxations in TSC. $P_{0}\left(\alpha\right.$, copo), i.e. $P_{0}$ for the copolymer $\alpha$ mode, is 6 times lower than for the terpolymer, while $\mathrm{P}_{0}$ (Curie, copo) is nearly 30 times higher. This opposite behavior of $\mathrm{P}_{0}($ Curie $)$ and $\mathrm{P}_{0}(\alpha)$ is attributed to the crystallinity ratio decrease due to CFE units. The activation entropy versus activation enthalpy for the $\alpha$ and Curie relaxations of these polymers are reported in Fig. 7.

\section{4. $\alpha$ relaxation mode}

For both polymers, the $\alpha$ relaxation is characterized by a compensation law between activation entropy and activation enthalpy. This behavior is associated with the $\alpha$ relaxation cooperativity. The activation enthalpy values for the $\alpha$ relaxation range from $100 \mathrm{~kJ} \mathrm{~mol}^{-1}$ to $280 \mathrm{~kJ} \mathrm{~mol}^{-1}$. These values are in good agreement with activation parameters of a dipolar relaxation associated with the glass transition [35-37]. The slopes of the terpolymer and copolymer plots are similar, indicating that the CFE units weakly influence the molecular dynamics in the amorphous phase. The activation enthalpy range for 

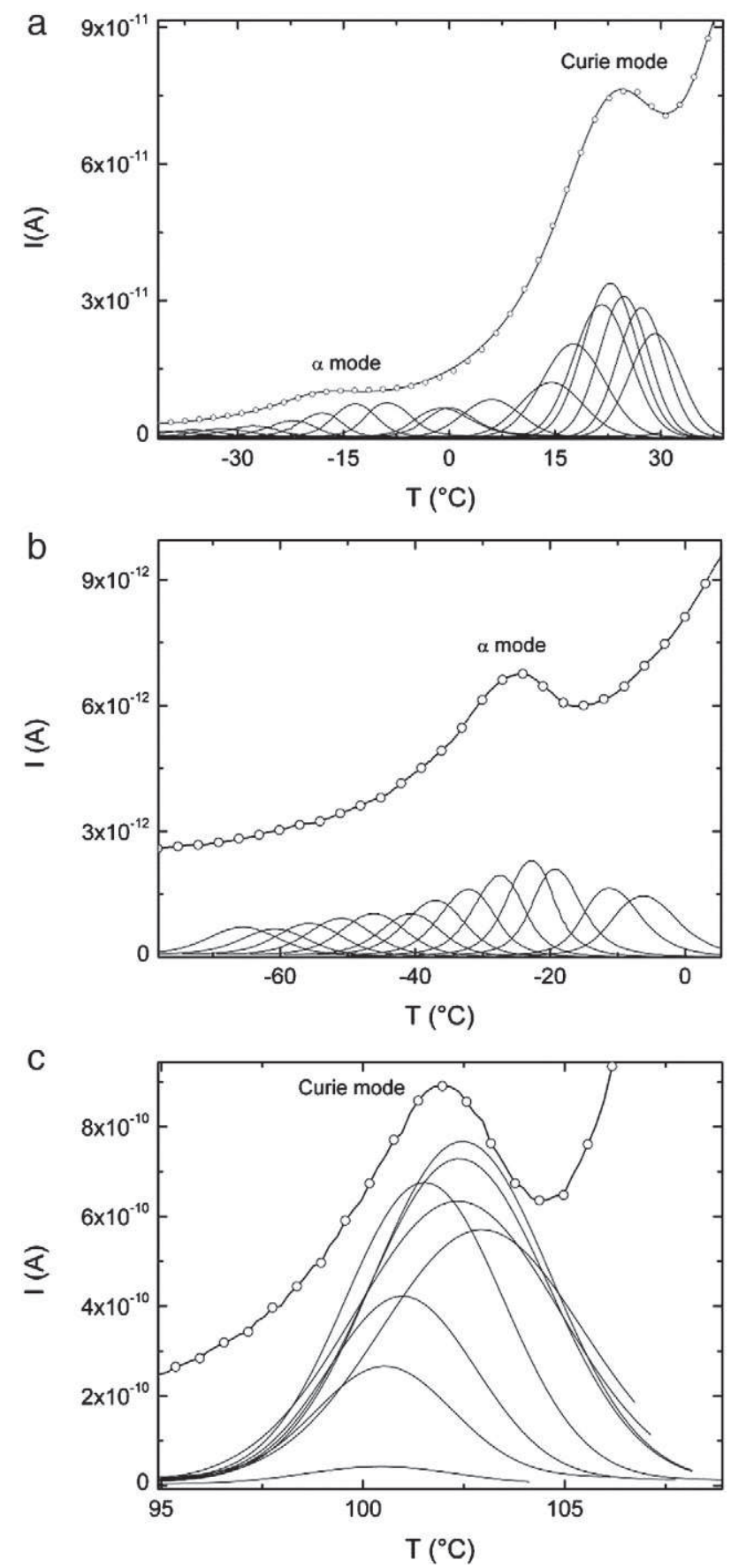

Fig. 4. Complex TSC thermograms and elementary TSC thermograms for the $\mathrm{P}(\mathrm{VDF}-\mathrm{TrFE}-\mathrm{CFE})$ terpolymer (a) and the P(VDF-TrFE) copolymer $(\mathrm{b}-\mathrm{c})$. Lines are given as guides to the eye.

the copolymer is $20 \%$ lower than for the terpolymer due to the lower crystallinity ratio of the terpolymer. It leads a less constrained amorphous phase with higher cooperative rearranging regions (CRR) size in the model introduced by Adam and Gibbs [38] and adapted by Donth $[39,40]$. The decrease of CRR [41-43] size with the decrease of the amorphous phase content report in this study is analogous with previously published data on the evolution of the CRR in ceramic/ polymer nanocomposites [44,45]: the densification of the composite with the increase of the inorganic phase volume fraction tends to reduce the activation enthalpy of the $\alpha$ process and consequently the size of the CRR.

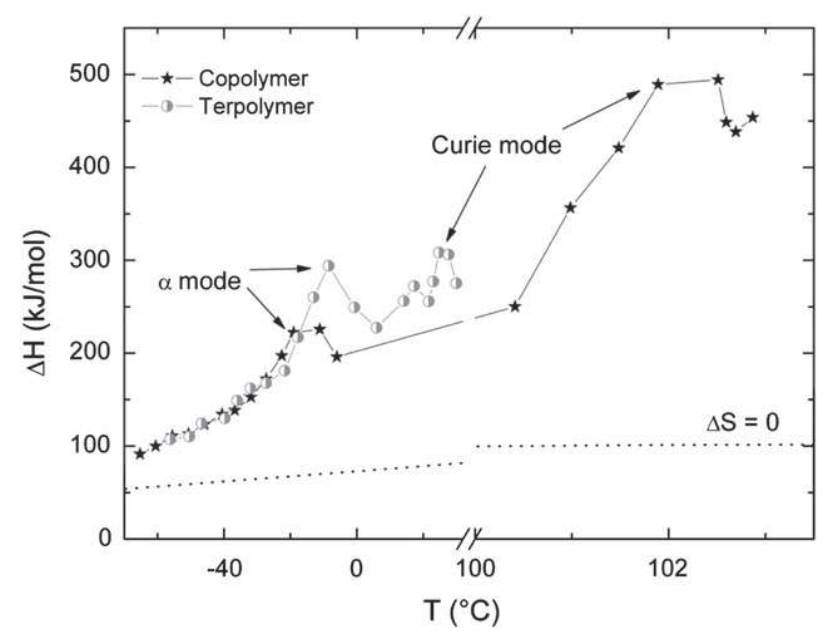

Fig. 5. Activation enthalpies $\Delta H$ extracted from elementary TSC thermograms versus temperature for the $\mathrm{P}(\mathrm{VDF}-\mathrm{TrFE}-\mathrm{CFE})$ terpolymer and the $\mathrm{P}(\mathrm{VDF}-\mathrm{TrFE})$ copolymer. Lines are given as guides to the eye.

\subsection{Curie relaxation mode}

The relaxation associated with the Curie transition has been assigned to dipolar reorientations in the crystalline phase of these semi-crystalline polymers. It has been shown that the CFE units strongly influence the crystalline phase by acting as defects. The compensation diagram of the copolymer and terpolymer is reported in Fig. 7. Activation enthalpies of the Curie relaxation are higher than for the $\alpha$ mode which is consistent
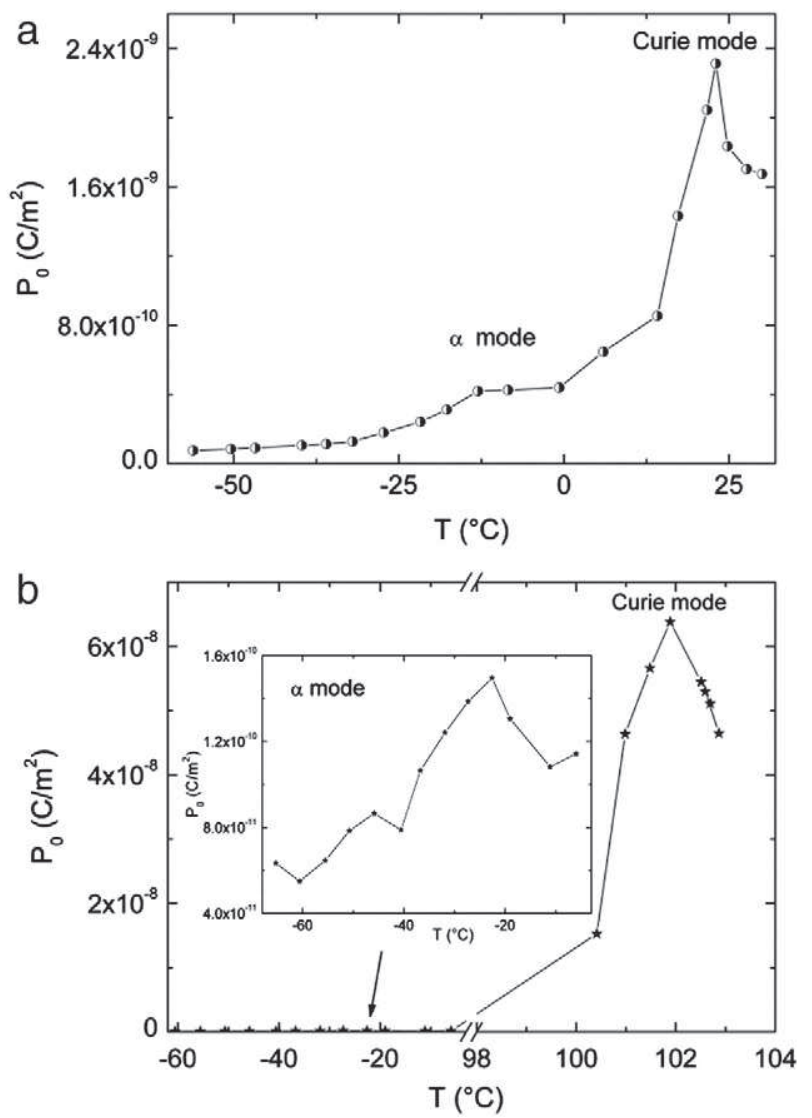

Fig. 6. Total polarization $P_{0}$ extracted from elementary TSC thermograms versus temperature for the P(VDF-TrFE-CFE) terpolymer (a) and the P(VDF-TrFE) copolymer (b). Lines are given as guides to the eye. 


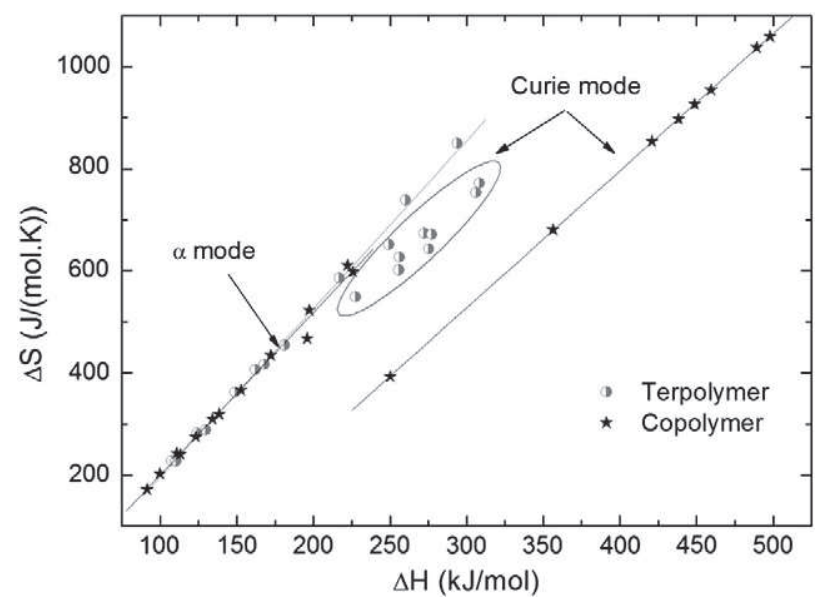

Fig. 7. Activation entropies $\Delta S$ versus enthalpies $\Delta H$ extracted from elementary TSC thermograms for the P(VDF-TrFE-CFE) terpolymer and the P(VDF-TrFE) copolymer. Lines are given as guides to the eye.

with the fact that the Curie mode is attributed to an order-disorder transition in a crystalline environment with higher potential barriers.

The decrease of the activation entropy for the Curie mode regarding the $\alpha$ one, reflected by the relative position of the two compensation lines, is consistent with the decrease of the number of accessible sites in the crystalline phase, regarding the amorphous phase. The narrow temperature range in which this relaxation take place $\left(\Delta \mathrm{T}=4{ }^{\circ} \mathrm{C}\right)$ reflects the homogeneity of the crystalline phase.

The Curie relaxation of the terpolymer is quite different. No compensation law is found and the activation enthalpies and entropies are close to the values reported for the $\alpha$ relaxation mode. This means that the Curie relaxation loses its cooperative behavior. Since the range of cooperativity is linked to the range of order, this is consistent with the small crystallite size near $-10 \mathrm{~nm}$ - induced by defects reported by Ang et al. [46] for the terpolymer in comparison with the submicronic crystallite size $(\leq 0.5 \mu \mathrm{m})$ of the copolymer. The temperature range of the Curie relaxation is $15{ }^{\circ} \mathrm{C}$. The CFE units tend to create defects in the crystalline phase creating a less ordered crystalline structure with heterogeneous morphologies.

The typical size of the terpolymer crystallites close to the CRR size of the amorphous phase and the non cooperative behavior of the Curie transition tend to indicate that the molecular dynamics at the glass transition highly affect the dynamic response of Curie mode. At low frequency, the $\alpha$ relaxation is far from the isothermal Curie relaxation. As the frequency increases, the temperature location of the $\alpha$ relaxation gets closer to the Curie relaxation until a merging frequency $\mathrm{f}_{\mathrm{m}}$. At $\mathrm{f}_{\mathrm{m}}$ the dielectric relaxor dynamic is activated by the relaxation associated with the vitreous transition.

\subsection{Ferroelectric behavior}

Fig. 8 presents the dielectric displacement (D) versus the applied electric field (E), is presented for the $\mathrm{P}(\mathrm{VDF}-\mathrm{TrFE})$ copolymer and the $\mathrm{P}$ (VDF-TrFE-CFE) terpolymer measured at room temperature. The applied electric field was a sinusoidal signal with a period of $18 \mathrm{~s}$. $\mathrm{P}(\mathrm{VDF}-\mathrm{TrFE})$ has a ferroelectric hysteresis loop characterized by a maximum polarization of about $25 \mathrm{mC} \mathrm{m}^{-2}$ and a large remnant polarization of $18 \mathrm{mC} \mathrm{m}^{-2}$. The large remnant polarization of the $\mathrm{P}$ (VDF-TrFE) copolymer indicates that most of the electrical energy injected in the material is stored by the cooperativity of the dipoles in the crystalline domains. As a consequence, at null electric field, it remains a macroscopic polarization that can only be reversed by applying an opposite electric field with a value up to the coercive

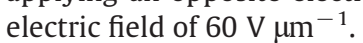

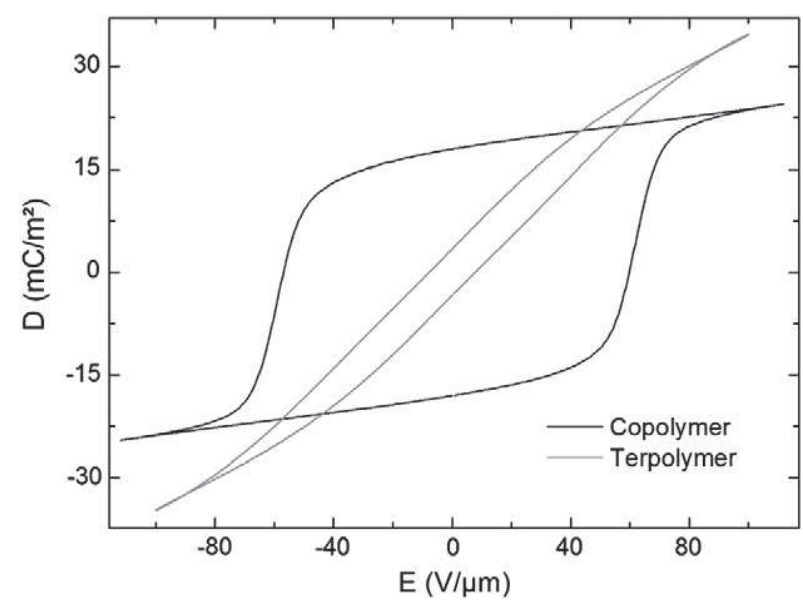

Fig. 8. Dielectric displacement versus applied electric field of the $\mathrm{P}(\mathrm{VDF}-\mathrm{TrFE})$ copolymer (black line) and the P(VDF-TrFE-CFE) terpolymer (gray line) measured at room temperature and under a sinusoidal signal with a period of $18 \mathrm{~s}$.

The $\mathrm{D}(\mathrm{E})$ curve of the $\mathrm{P}(\mathrm{VDF}-\mathrm{TrFE}-\mathrm{CFE})$ terpolymer is a mix between a High-K $\mathrm{D}(\mathrm{E})$ curve of a normal dielectric material (large maximum polarization of $35 \mathrm{mC} \mathrm{m}^{-2}$ ) and a poorly ferroelectric hysteresis cycle characterized by a low remnant polarization of $4 \mathrm{mC} \mathrm{m}^{-2}$. As the electric field is increased, dipoles in the crystalline phase are oriented. Most of the electrical energy injected in the terpolymer is recovered when the electric field is turned off. The cooperativity of the dipolar mobility requires long range order. Consequently, the lack of cooperativity observed in the terpolymer may be assigned to the reduction of the crystalline region inducing a loss of ferroelectric behavior.

\section{Conclusion}

The understanding of the molecular origin of the dielectric relaxor behavior of fluorinated terpolymers is crucial because of their potential applications in electro-mechanical transduction systems. The molecular dynamics, the cooperativity of the dipolar entities involved in the Curie transition and the thermal properties have been characterized by DSC and dielectric experiments. A comparative study of a fluorinated terpolymer and a copolymer allows us to quantify the role of the CFE units on the relaxor like behavior of the P(VDF-TrFE-CFE) terpolymer. CFE units tend to reduce the size of crystallites, cohesive energy, and the rate of crystallinity. The molecular dynamics of the relaxation associated with the glass transition are quite similar in the terpolymer and the copolymer. Moreover, the decrease of the crystallinity with CFE units results in larger CRR size as defined from the relaxation associated with Tg.

The most important point is the loss of the cooperative behavior of the Curie transition in the ferroelectric relaxor terpolymer. The activation enthalpies of the Curie relaxation of the terpolymer remain close to those involved in the relaxation associated with $\mathrm{Tg}$. This result is consistent with the fact that the crystallite size is of the same order than the CRR size which is not sufficient for cooperativity. Above the merging frequency $f_{m}$, the $\alpha$ process associated with $T_{g}$ governs the dielectric behavior of the relaxor.

\section{References}

[1] H. Kawai, Jpn. J. Appl. Phys. 8 (1969) 975-976.

[2] A.J. Lovinger, Science 220 (1983) 1115-1121.

[3] M. Oshiki, E. Fukada, J. Mater. Sci. 10 (1975) 1-6.

[4] L. Ibos, A. Bernes, C. Lacabanne, Ferroelectrics 320 (2005) 15-21.

[5] E. Riande, R. Diaz Calleja, Electrical properties of polymers, chapter 12 (2004) 497-541

[6] C.J. Dias, D.K. Das Gupta, IEEE Trans. Dielectr. Electr. Insul. 3 (1996) 706-734.

[7] S.W. Or, H.L.W. Chan, C.L. Choy, Sens. Actuators 80 (2000) 237-241. 
[8] S.S. Guo, W.P. Li, K. Li, H.L.W. Chan, X.Z. Zhao, C.L. Choy, Sens. Actuators A 112 (2004) 134-141.

[9] N. Snis, E. Edqvist, U. Simu, S. Johansson, Sens. Actuators A 144 (2008) 314-320.

[10] K. Müller, I. Paloumpa, K. Henkel, D. Schmeiber, Mater. Sci. Eng. C 26 (2006) $1028-1031$.

[11] K. Lee, K. Lee, M.S. Oh, J.M. Choi, S. Im, S. Jang, E. Kim, Org. Electron. 10 (2009) 194-198.

[12] J.I. Scheinbeim, J.W. Lee, B.A. Newman, Macromolecules 25 (1992) 3729-3732.

[13] J.F. Capsal, E. Dantras, J. Dandurand, C. Lacabanne, Polymer 51 (2010) 4606-4610.

[14] G.A. Samara, F. Bauer, Ferroelectrics 135 (1992) 385-399.

[15] H. Wang, Q.M. Zhang, E. Cross, A.O. Sykes, J. Appl. Phys. 74 (1993) 3394-3398

[16] Q.M. Zhang, V. Bharti, X. Zhao, Science 280 (1998) 2101-2104.

[17] R.J. Klein, J. Runt, Q.M. Zhang, Macromolecules 36 (2003) 7220-7226.

[18] H. Xu, Z.Y. Cheng, D. Olson, T. Mai, Q.M. Zhang, Appl. Phys. Lett. 78 (2001) $2360-2362$.

[19] R. Klein, F. Xia, Q.M. Zhang, F. Bauer, J. Appl. Phys. 97 (2005) 094105-1-094105-4.

[20] T.C. Chung, A. Petchsuk, Macromolecules 35 (2002) 7678-7684

[21] V. Bobnar, B. Vodopivec, A. Levstik, M. Kosec, B. Hilczer, Q.M. Zhang, Macromolecules 36 (2003) 4436-4442.

[22] J.W. Wang, Q.D. Shen, H.M. Bao, C.Z. Yang, Q.M. Zhang, Macromolecules 38 (2005) 2247-2252.

[23] F. Bauer, E. Fousson, Q.M. Zhang, L.M. Lee, IEEE Trans. Dielectr. Electr. Insul. 11 (2004) 293-298

[24] G. Teyssedre, C. Lacabanne, J. Phys. D Appl. Phys. 28 (1995) 1478-1487.

[25] H.M. Bao, J.F. Song, J. Zhang, Q.D. Shen, C.Z. Yang, Q.M. Zhang, Macromolecules 40 (2007) 2371-2379.

[26] T. Furukawa, Phase Transitions 18 (1989) 143-211.

[27] J.F. Legrand, Ferroelectrics 91 (1989) 303-317.
[28] A. Lonjon, L. Laffont, P. Demont, E. Dantras, C. Lacabanne, J. Phys. D Appl. Phys. 43 (345401) (2010) 1-7.

[29] J.F. Capsal, E. Dantras, J. Dandurand, C. Lacabanne, J. Non-Cryst. Solids 358 (2012) 794-798.

[30] B.B. Sauer, P. Avakian, H.W. Starkweather, B.S. Hsaio, Macromolecules 23 (1990) 5119-5126.

[31] E. Dantras, C. Lacabanne, A.M. Caminade, J.P. Majoral, Macromolecules 34 (2001) 3808-3811.

[32] C. Lacabanne, D. Chatain, J. Phys. Chem. 3 (1975) 283-287.

[33] G. Teyssedre, S. Mezghani, A. Bernes, C. Lacabanne, in: J. Runt, J. Fitzgerald (Eds.), Dielectric Spectroscopy of Polymeric Materials, 1997, p. 227.

[34] H.W. Starkweather, Macromolecules 14 (1981) 1277-1281.

[35] E. Dudognon, A. Bernes, C. Lacabanne, Macromolecules 34 (2001) 3988-3992.

[36] E. Dudognon, A. Bernes, C. Lacabanne, Macromolecules 35 (2002) 5927-5931.

[37] G. Jafarpour, E. Dantras, A. Boudet, C. Lacabanne, J. Non-Cryst. Solids 354 (2008) 3207-3214.

[38] G. Adam, J.H. Gibbs, J. Chem. Phys. 43 (1965) 139-146.

[39] E. Donth, J. Polym. Sci. B 34 (1996) 2881-2892.

[40] E. Donth, Acta Polym. 50 (1999) 240-251.

[41] N. Delpouve, A. Saiter, J.F. Mano, E. Dargent, Polymer 49 (2008) 3130-3135.

[42] C. Lixon, N. Delpouve, A. Saiter, E. Dargent, Y. Grohens, Eur. Polym. J. 44 (2008) 3377-3384.

[43] A. Saiter, N. Delpouve, E. Dargent, J.M. Saiter, Eur. Polym. J. 43 (2007) 4675-4682.

[44] C. Sender, J.F. Capsal, A. Lonjon, A. Bernes, P. Demont, E. Dantras, L. Laffont, V. Samouillan, J. Dandurand, C. Lacabanne, in: L. Utracki, A.M. Jamieson (Eds.), Polymer Physics: From Suspensions to Nanocomposites to Beyond, John Wiley, 2009.

[45] A.N. Khan, P.D. Hong, W.T. Chuang, K.S. Shih, Polymer 50 (2009) 6287-6296.

[46] C. Ang, Z. Yu, Appl. Phys. Lett. 86 (2005), (262903-262903-3). 